\title{
Nutritional Intervention in Chronic Liver Failure
}

\author{
Mathias Plauth \\ Department of Internal Medicine, Community Hospital Dessau, Dessau-Rosslau, Germany
}

Keywords

Nutritional intervention - Chronic liver failure · Malnutrition . Sarcopenia

\section{Abstract}

Patients suffering from chronic liver failure (CLF) frequently are malnourished and do not achieve an adequate intake of nutrients, in particular protein. Low protein intake and loss of muscle mass and function, termed sarcopenia, are indicators of a poor outcome. CLF patients, therefore, should be screened for risk of malnutrition using a validated tool, and if positive, full assessment of nutritional status is mandatory including search for sarcopenia. The main goal of nutritional intervention is to provide enough protein (1.2-1.5 $\mathrm{g} \times \mathrm{kg}^{-1} \times$ day $^{-1}$ ) and to ensure adequate energy intake (total energy $30 \mathrm{kcal} \times \mathrm{kg}^{-1} \times$ day $^{-1} ; 1.3 \times$ resting energy expenditure). Livers of CLF patients are deplete in glycogen and, therefore, prolonged periods of fasting ( $>12 \mathrm{~h}$ ) must be avoided in order to prevent further breakdown of muscle protein for gluconeogenesis. Therefore, late evening snacks or even nocturnal oral nutritional supplements improve total body protein status and thus, are recommended. Nutrition intervention should be stepped up from nutrition counselling to oral nutritional supplements, to enteral tube feeding, or to parenteral nutrition as appropriate. As in other malnourished patients, the prevention of refeeding syndrome or vitamin/trace element deficiency should be taken care of.

\footnotetext{
(c) 2019 S. Karger AG, Basel
}

\section{Introduction}

Nutrition has long been recognized a prognostic and therapeutic determinant in patients with chronic liver disease and has therefore been included as one of the variables in the original prognostic score introduced by Child and Turcotte [1].

\section{Nutritional Risk in Chronic Liver Failure Patients}

Adequate nutrition can be viewed as a complex action by which a healthy organism responds to various challenges in a flexible adaptive manner. Therefore, the assessment of nutritional risk of patients must include a measure of the physiologic capabilities - the nutritional status - and the burden inflicted by the ongoing or impending disease and/or medical interventions. Thus, a meaningful assessment of nutritional status should encompass not only body weight and height, but information on energy and nutrient balance as well as body composition and tissue function reflecting the metabolic and physical fitness of the patient facing a vital contest. Furthermore, such information is stronger when available with a dynamic view (e.g., weight loss per time).

Numerous descriptive studies have shown higher rates of mortality and complications, such as refractory ascites, variceal bleeding, infection, and hepatic encephalopathy (HE) in cirrhotic patients with protein malnutrition as

\section{KARGER}

(C) 2019 S. Karger AG, Basel
Mathias Plauth

Klinik für Innere Medizin I, Städtisches Klinikum Dessau

Auenweg 38

DE-06847 Dessau-Rosslau (Germany)

E-Mail mathias.plauth@klinikum-dessau.de 
well as reduced survival when such patients undergo liver transplantation or other abdominal surgery [2]. NRS2002 and MUST are validated tools to screen hospitalized patients for risk of malnutrition. The Royal Free Hospital Nutrition Prioritization Tool (RFH-NPT) has been developed as a screening tool for malnutrition in liver disease patients [3]. In a head-to-head comparison, the RFH-NPT was more sensitive than the NRS-2002 to identify liver patients at risk for malnutrition [4]. Therefore, the recent ESPEN guidelines recommend using the RFHNPT in patients with chronic liver failure (CLF) [2].

In CLF, poor oral food intake is a predictor of increased mortality. In nutrition intervention trials, patients with the lowest spontaneous energy intake showed the highest mortality [5]. In clinical practice, the plate protocol of Nutrition Day [6] is an easy to use and reliable tool to assess food intake in hospitalized patients.

Simple bedside methods like the Subjective Global Assessment (SGA) or anthropometry have been used to identify malnutrition. The accurate quantitative measurement of nutritional status is difficult in chronic liver disease patients with fluid overload and/or impaired hepatic protein synthesis and requires sophisticated methods such as total body potassium count or in vivo neutron activation analysis or isotope dilution [2].

In patients with CLF, nutritional status can be assessed using bedside methods, such as the SGA or the modified Royal Free Hospital SGA (RFH-SGA) combining SGA and anthropometry [7]. The RFH-SGA proved to be a strong predictor of morbidity and mortality, but it is time-consuming and requires a trained dietician.

Handgrip strength is lower in protein-depleted cirrhotics and is a good predictor of the rate of complications within the next year. Handgrip strength is a valuable tool to measure efficacy of nutritional intervention [2].

In liver cirrhosis (LC), patients' reactance and resistance readouts from bioimpedance analysis can be used to calculate phase angle as a measure of cell mass and cell function or body cell mass for the assessment of nutritional state. In LC, low phase angle is associated with increased mortality as in many other disease entities $[8,9]$.

\section{Effect of Chronic Liver Disease on Nutritional State}

\section{Cirrhosis}

Prevalence and severity of malnutrition are related to the clinical stage of chronic liver disease, increasing from $20 \%$ of patients with well-compensated disease up to more than $60 \%$ of patients with severe liver insufficiency [10]. Sarcopenia is the key feature of malnutrition in LC patients and shall be diagnosed by radiologic methods (DXA, CT) to detect loss of muscle mass or by tests of muscle function such as exercise test or 6-min walk dis- tance. Sarcopenia can be diagnosed when there is loss of muscle mass or muscle function. On CT images, at the level of lumbar vertebra 3 , skeletal muscle area can be measured and normalized for stature by calculating the skeletal muscle index as a measure of whole-body muscle mass. Loss of skeletal muscle mass on CT has been shown to indicate an increased mortality in cirrhotics [11], obese CLF patients, and orthotopic liver transplantation recipients [2]. After transjugular intrahepatic portosystemic stent-shunt, failure to reverse sarcopenia was associated with poorer survival, and after transplantation, new-onset sarcopenia was associated with a trend for higher mortality [2].

In CLF patients on the wait list, loss of muscle function in terms of 6-min walk distance, grip strength, and the short physical performance battery, but not loss of muscle mass in terms of CT-derived skeletal muscle index, have been shown to be associated with increased mortality. In CLF patients, frailty experienced as a functional decline in grip strength, gait speed, chair stands, or short physical performance battery has been shown to be associated with increased risk for complications requiring hospitalization or death on the wait list or delisting $[2,12]$.

In CLF patients, there is a profound reduction in exercise capacity, and in the majority of patients, this reduction is only moderately ameliorated after transplantation. CLF patients with a $\mathrm{VO}_{2} \max <60 \%$ of normal had a $50 \% 1$-year survival when transplanted [13]. Actively exercising transplant recipients, however, can bring their $\mathrm{VO}_{2}$ max back to normal [14].

Recovery from this loss in body cell mass can be achieved by the control of complications such as portal hypertension and adequate nutrition $[15,16]$. Etiology of liver disease per se does not seem to influence the prevalence and degree of malnutrition and protein depletion, and the higher prevalence and more profound degree of malnutrition in alcoholics obviously result from unhealthy life style and low socioeconomic conditions [2].

In hospitalized cirrhotics, fatigue, somnolence, or psychomotor dysfunction often lead to insufficient oral nutrition even in the absence of overt HE. Fat malabsorption and steatorrhea do occur in cholestatic liver disease, such as primary biliary cholangitis or cystic fibrosis, leading to severe malabsorption of dietary fat as well as fat-soluble vitamins.

\section{Pathophysiology and Nutrient Requirement in Chronic Liver Failure}

\section{Energy}

Measurement of resting energy expenditure (REE) in CLF and in controls showed no difference when REE was related to body surface area or body mass (LC: $22-27 \mathrm{kcal}$ $\left.\times \mathrm{kg} \mathrm{BW}^{-1} \times \mathrm{day}^{-1}\right)$ [2]. REE showed increased values in 
CLF when REE was related to lean body mass in terms of urinary creatinine excretion or in terms of body cell mass [2]. In alcoholics without biochemical evidence of liver disease, but not in patients with alcoholic LC, an increased $\operatorname{REE}\left(25.8\right.$ vs. $20.8 \mathrm{kcal} \times \mathrm{kg} \mathrm{BW}^{-1} \times \mathrm{day}^{-1}$ ) was observed. Likewise, in patients with alcoholic liver disease, alcohol abuse was associated with increased REE (26\%); a decrease in REE consistently occurred 4 days after abstinence from alcohol [17].

On average, measured REE is of the same magnitude as energy expenditure predicted by use of formulae (Harris and Benedict, Schofield, etc.) [2]. Measured REE is higher than predicted REE in up to $35 \%$ of cirrhotic patients (hypermetabolism) and below the predicted value in $18 \%$ of the patients. In cirrhosis, hypermetabolism has been shown to be associated with reduced event-free survival and unfavorable outcome after transplantation and seems to regress with improvement of body composition and after liver transplantation [2].

The spontaneous physical activity level is considerably lower in patients with cirrhosis compared to healthy individuals [18]. Obviously, the increased energy requirement in advanced illness is balanced by diminished physical activity reflecting the poor physical condition. Measurements of total energy expenditure indicate that the 24-hour energy requirement of cirrhosis patients amounts to about $130 \%$ of the basal metabolic rate [2].

In cirrhotics without ascites, the actual body weight should be used for the calculation of the basal metabolic rate using formulae such as that proposed by Harris and Benedict. In underweight or normal weight patients with ascites, actual weight, and in overweight/obese patients, ideal weight according to body height should be used.

\section{Carbohydrate Metabolism}

The utilization of oxidative fuels is characterized by an increased rate of lipid oxidation in the fasting state and the frequent occurrence of insulin resistance (even in Child-Pugh class A patients) [2]. In the postabsorptive state, glucose oxidation rate is reduced and hepatic glucose production rate is low despite increased gluconeogenesis due to a depletion of hepatic glycogen. Up to $40 \%$ of patients develop overt diabetes, indicating an unfavorable prognosis [2].

\section{Fat Metabolism}

In the fasting state, the plasma levels of free fatty acids, glycerol, and ketone bodies are increased and free fatty acid and glycerol concentrations do not fully respond to low insulin infusion rates as in healthy subjects. Lipids are oxidized as the preferential substrate and lipolysis is increased with active mobilization of lipid deposits [2]. After a meal, plasma clearance and lipid oxidation rates are not reduced, showing a normal capacity to utilize exog- enous fat. Plasma levels of essential and polyunsaturated fatty acids are decreased in cirrhosis, and this decrement correlates to nutritional status and severity of liver disease.

\section{Protein and Amino Acid Metabolism}

Stable cirrhotics are capable of efficient nitrogen retention and significant formation of lean body mass from increased protein intake during oral refeeding. Protein catabolism influences the amino acid imbalance of cirrhosis and indirectly causes nitrogen overload to the liver, leading to hyperammonemia. In cirrhotics, after an overnight fast, glycogen stores are depleted and metabolic conditions are similar to prolonged starvation in healthy individuals. It has been shown that a late evening carbohydrate snack or nocturnal feeding of oral nutritional supplements (ONS) were associated with improved protein metabolism in cirrhotic patients [19]. Insulin resistance apparently is without effect on amino acid disposal.

Patients with stable cirrhosis have an increased protein requirement leading to a recommended provision of 1.2 $\mathrm{g} \times \mathrm{kg} \mathrm{BW}^{-1} \times \mathrm{day}^{-1}$, which is higher than intake of $0.8 \mathrm{~g}$ $\times \mathrm{kg} \mathrm{BW}^{-1} \times$ day $^{-1}$ recommended to maintain protein status in healthy humans [2].

Cirrhotic patients exhibit an altered pattern of plasma amino acids characterized by the elevation of aromatic (phenylalanine, tyrosine) and sulfur-containing amino acids (methionine) and tryptophan on the one hand and the decrease in branched-chain amino acids (BCAA) (leucine, isoleucine, valine) on the other hand. Decreased metabolic clearance by the failing liver of aromatic and sulfurous amino acids and increased breakdown in skeletal muscle of BCAA due to portal systemic shunting and hyperammonemia are discussed as causal [2].

Recently, it has been pointed out that, due to the absence of isoleucine from hemoglobin, blood is a protein source of low biologic value leading to BCAA antagonism after upper gastrointestinal hemorrhage. This BCAA antagonism readily explains the long known clinical observation that blood and vegetable protein represent the two extremes in the hierarchy of food proteins regarding their comagenic potential. Moreover, this antagonism leading to hyperammonemia could be overcome by the infusion of just isoleucine [20].

\section{Vitamins and Minerals}

The altered body composition of cirrhosis with protein depletion and overhydration goes hand in hand with salt retention, which therefore does not usually lead to hypernatremia. On the contrary, depletion of potassium, magnesium, phosphate, and other intracellular minerals is frequent. Deficiency in water-soluble vitamins, mainly group B vitamins, is common in cirrhosis, especially that of alcoholic origin [2]. Therefore, malnourished patients with 
CLF are at high risk for refeeding syndrome and appropriate measures should be taken before nutrition therapy is commenced. In particular, thiamine must be provided before the first dose of carbohydrate in order to prevent Wernicke's encephalopathy or lactic acidosis [21].

Deficiency in fat-soluble vitamins has been observed in cholestasis-related steatorrhea, bile salt deficiency, and in alcoholics. Zinc and selenium deficiencies have been observed in alcoholic and non-alcoholic liver disease [2].

\section{Nutrition Therapy in Patients with Chronic Liver Failure}

In patients with cirrhosis, the primary goal is to ensure a quantitatively adequate nutrient intake. Increasing protein intake by nutrition therapy can decrease mortality [2, 22 ], and adequate nutrition after successful treatment of portal hypertension by transjugular intrahepatic portosystemic stent-shunt has the potential to improve body composition $[15,16]$. Patients with CLF should achieve a total energy intake of $30 \mathrm{kcal} \times \mathrm{kg} \mathrm{BW}^{-1} \times \mathrm{day}^{-1}$ and a protein intake of $1.2-1.5 \mathrm{~g} \times \mathrm{kg} \mathrm{BW}^{-1} \times \mathrm{day}^{-1}$ [2].

Regarding the method of nutritional intervention, nutritional counselling alone or in combination with oral nutrition supplements is an effective first-line intervention [2]. Supplemental enteral nutrition (EN) using a standard whole-protein formula should be given when patients with LC cannot meet their nutritional requirements from normal food despite adequate individualized nutritional counselling. Very often, the spontaneous food intake of nonencephalopathic patients with CLF is overestimated and the therapeutic potential by the timely use of tube feeding is underused. Also, in subclinical or mild HE, due to somnolence and psychomotor dysfunction, oral nutrition often is insufficient (grade I-II). Diets containing $1.2 \mathrm{~g} \times \mathrm{kg}$ $\mathrm{BW}^{-1} \times$ day $^{-1}$ protein can safely be administered to patients with cirrhosis suffering from episodic $\mathrm{HE}$, and - even transient - protein restriction did not confer any benefit to patients during an episode of encephalopathy [23, 24].

Patients with LC suffer from a depletion of hepatic glycogen stores and thus are less prepared to adequately master periods of even short-term food deprivation. A late evening carbohydrate snack can improve protein metabolism in cirrhotics [19]. Recently, it has been shown that nocturnal oral supplements, i.e., given after 21:00 h, are more efficient in improving total body protein status of cirrhotic patients than isonitrogenous and isocaloric amounts given during daytime [25].

In stable cirrhotics, formulae enriched in BCAA are not necessary. Such formulae are helpful in the very select subgroup of protein-intolerant patients with $\mathrm{HE}$ [26]. In stable patients with cirrhosis, long-term (12 and 24 months) nutritional supplementation with oral BCAA granules as oral nutrition supplement has the potential to slow the progression of hepatic failure and prolong eventfree survival $[27,28]$, but this treatment is not reimbursed in many countries. When patients develop HE during EN, BCAA-enriched formulae should be used [2].

Regarding trace elements and vitamins, in a pragmatic approach, liberal supplementation is recommended in the first 2 weeks of nutritional support. Oral zinc supplementation as a treatment of $\mathrm{HE}$ has been disappointing in controlled trials, despite encouraging case reports. Supplementing zinc and vitamin A may indirectly improve food intake and nutritional state by improving dysgeusia [2].

In patients with unprotected airways and advanced $\mathrm{HE}$ where swallow and cough reflexes are compromised, the risk of aspiration should be considered when deciding on whether to feed by the enteral or the parenteral route. Tube feeding is not contraindicated in the presence of esophageal varices but the use of PEGs in cirrhotics is discouraged [2]. Parenteral nutrition (PN) is a valuable second-line option and must be implemented immediately when moderately or severely malnourished cirrhotics cannot be nourished sufficiently by either oral or enteral route. In analogy to the observations regarding the benefit of nocturnal oral supplements, every patient with CLF who needs to be managed nil by mouth for more than $12 \mathrm{~h}$ (including nocturnal fasting!) should be given i.v. glucose at $2-3 \mathrm{~g} \times \mathrm{kg} \mathrm{BW}^{-1} \times$ day $^{-1}$ as the minimum metabolic intervention. When this fasting period lasts longer than $72 \mathrm{~h}$, total PN should be implemented and, as an intermediary measure, hypocaloric peripheral $\mathrm{PN}$ may be used when fasting periods are expected to last for less than $72 \mathrm{~h} \mathrm{[2].}$

If $\mathrm{PN}$ is used as the exclusive form of nutrition, then the i.v. provision of all macro- and micronutrients must be ensured from the beginning of total PN. Carbohydrate should be given as glucose to cover $50-60 \%$ of non-protein energy requirements $\left(25 \mathrm{kcal} \times \mathrm{kg} \mathrm{BW}^{-1} \times \mathrm{day}^{-1}\right)$. The simultaneous infusion of lipid and glucose provides a better metabolic profile than glucose alone. Regarding the optimal composition of i.v. oxidative fuels fat and carbohydrate, only limited information is available [2]. The ESPEN guidelines recommend fat provision to cover 40 $50 \%$ of non-protein energy requirements using emulsions with a lower content of n-6 unsaturated fatty acids than in traditional pure soy bean oil emulsions [2].

The infusion of amino acids should provide an amount of $1.2 \mathrm{~g} \times \mathrm{kg} \mathrm{BW}^{-1} \times \mathrm{day}^{-1}$ in compensated cirrhosis without malnutrition and $1.5 \mathrm{~g} \times \mathrm{kg} \mathrm{BW}^{-1} \times \mathrm{day}^{-1}$ in decompensated cirrhosis with severe malnutrition. In clinical trials, studying patients with LC and severe HE, the provision of protein or amino acids ranged from 0.6 to $1.2 \mathrm{~g} \times$ $\mathrm{kg} \mathrm{BW}^{-1} \times$ day $^{-1}[2]$. In patients with alcoholic hepatitis or alcoholic cirrhosis with or without low-grade HE, the provision ranged from 0.5 to $1.6 \mathrm{~g} \times \mathrm{kg} \mathrm{BW}^{-1} \times \mathrm{day}^{-1}$ [2]. For $\mathrm{PN}$ in patients with compensated cirrhosis, amino 
acid solutions with a special "hepatic formula" composition are not required.

For PN of cirrhotics with overt HE, amino acid solutions with a special "hepatic formula" high in BCAA (35$45 \%$ ) but low in tryptophan, aromatic, and sulfur-containing amino acids were developed. Such solutions help to correct the amino acid imbalance in LC. A meta-analysis showed an improvement in mental state by the BCAA-enriched solutions, but no definite benefit in survival [29]. A BCAA-enriched complete amino acid solution should be given in more severe HE (grade III-IV).

Blood from gastrointestinal hemorrhage is a protein source of low biologic value leading to BCAA antagonism. This antagonism leads to hyperammonemia, but HE could be overcome by the infusion of just isoleucine [20]. Isoleucine solutions for i.v. infusions, however, are not commercially available. Special hepatic formula amino acid solutions (cf. above) contain high amounts of isoleucine and of the other BCAAs, leucine and valine.

Nutrition therapy prior to elective surgery should be managed according to the recommendations given for the underlying disease, which most likely is LC in the majority of cases. In malnourished patients with CLF, the risk of postoperative morbidity and mortality is increased after abdominal surgery [30]. Liver glycogen is depleted in LC patients and therefore, it is advisable to take great care to shorten periods without nutrient intake. Also in liver surgery, adoption of ERAS protocols improves morbidity and length of stay when, among other measures, patients are given carbohydrate-containing clear liquid until $2 \mathrm{~h}$ preoperatively, early feeding, and mobilization $[2,31]$.

Sarcopenic LC patients undergoing non-transplant surgery like resection for HCC have an increased mortality risk [32]. In LC patients undergoing non-transplant visceral surgery, complication rate and nitrogen economy can be improved when nutrition support instead of just fluid and electrolytes is provided. It may safely be assumed that EN in the early postoperative period would yield at least equal results [2].

Numerous descriptive studies have shown higher morbidity and mortality in LC patients with protein malnutrition when such patients undergo liver transplantation $[33,34]$. Recently, sarcopenia and frailty have been shown to carry an increased risk of morbidity and mortality for patients on the waiting list and after transplantation $[2,11,35-38]$. Patients on the wait list are at risk due to an inadequately low food intake, and those consuming a low protein diet $\left(<0.8 \mathrm{~g} \times \mathrm{kg} \mathrm{BW}^{-1} \times\right.$ day $\left.^{-1}\right)$ have an increased wait-list mortality [2].

Nevertheless, there are no formal trials showing that preoperative nutritional intervention improves clinical outcome. Data from a pilot study suggest that preoperative nutrition support improves total body protein status and reduces postoperative infection rates [39]. In less advanced and predominantly cholestatic LC, nutritional counselling plus ONS improved mid-arm muscle circumference and grip strength compared to nutritional counselling alone, while there was no difference in mortality [40]. Despite promising results from pilot studies, perioperative immunonutrition did not provide significant benefits in terms of preoperative total body protein status or postoperative outcome compared to standard ONS in a randomized trial [41]. Kaido and colleagues [42] observed less postoperative infections in their transplanted patients who received preoperative BCAA-enriched ONS. Interestingly, BCAA supplementation conferred better survival only to sarcopenic patients on the waiting list but not to non-sarcopenic individuals [36]. Pediatric transplant patients with predominantly cholestatic liver disease show a better increase in body cell mass if they are given a BCAAenriched formula [43].

After transplantation, early EN (12 h after the operation) is associated with fewer viral infections and better nitrogen retention than $\mathrm{PN}$. In a direct comparison between PN and early EN, both strategies proved to be equally effective with regard to the maintenance of nutritional state, but EN reduced complication rate and cost. For early EN in adult liver transplant recipients, whole-protein formulae with [44] or without pre- and probiotics or peptide-based formulae via catheter jejunostomy have been used [2].

Long-term survivors after liver transplantation are at considerable risk of developing sarcopenic obesity and metabolic syndrome $[2,45,46]$. In the last decade, an increasing number of overweight or frankly obese patients with cirrhosis are seen. Obesity is an independent risk factor for decompensation; successful lifestyle intervention can reduce portal hypertension in such patients $[47,48]$.

\section{Key Messages}

- Expect severe malnutrition requiring immediate treatment.

- Protein malnutrition and hypermetabolism are associated with poor prognosis.

- Provide enough protein (1.2-1.5 $\left.\mathrm{g} \times \mathrm{kg} \mathrm{BW}^{-1} \times \mathrm{day}^{-1}\right)$.

- Ensure adequate energy intake (total energy $30 \mathrm{kcal} \times \mathrm{kg}$ $\mathrm{BW}^{-1} \times$ day $^{-1} ; 1.3 \times$ resting energy expenditure) .

- Avoid prolonged ( $>12 \mathrm{~h}$ ) periods without food/nutrition.

- Avoid refeeding syndrome or vitamin/trace element deficiencies.

- Use BCAA after GI-bleeding and in III/IV-degree HE.

- Use fat as fuel.

- Use enteral tube or sip feeding.

- Use parenteral nutrition if enteral feeding alone is not sufficient.

- Use indirect calorimetry if available. 
1 Child CG, Turcotte JG. Surgery and portal hypertension. In: Child CG, editor. The liver and portal hypertension. Philadelphia: Saunders; 1964. pp. 50-1.

2 Plauth M, Bernal W, Dasarathy S, Merli M, Plank LD, Schütz T, et al. ESPEN guideline on clinical nutrition in liver disease. Clin Nutr. 2019 Apr;38(2):485-521.

3 Amodio P, Bemeur C, Butterworth R, Cordoba J, Kato A, Montagnese S, et al. The nutritional management of hepatic encephalopathy in patients with cirrhosis: International Society for Hepatic Encephalopathy and Nitrogen Metabolism Consensus. Hepatology. 2013 Jul;58(1):325-36.

4 Borhofen SM, Gerner C, Lehmann J, et al. The Royal Free Hospital-Nutritional Prioritizing Tool Is an Independent Predictor of Deterioration of Liver Function and Survival in Cirrhosis. Dig Dis Sci. 2016 Jun;61(6):1735-43.

5 Kondrup J, Müller MJ. Energy and protein requirements of patients with chronic liver disease. J Hepatol. 1997 Jul;27(1):239-47.

6 Hiesmayr M, Schindler K, Pernicka E, Schuh C, Schoeniger-Hekele A, Bauer P, et al.; NutritionDay Audit Team. Decreased food intake is a risk factor for mortality in hospitalised patients: the NutritionDay survey 2006. Clin Nutr. 2009 Oct;28(5):484-91.

7 Morgan MY, Madden AM, Soulsby CT, Morris RW. Derivation and validation of a new global method for assessing nutritional status in patients with cirrhosis. Hepatology. 2006 Oct;44(4):823-35.

8 Selberg O, Selberg D. Norms and correlates of bioimpedance phase angle in healthy human subjects, hospitalized patients, and patients with liver cirrhosis. Eur J Appl Physiol. 2002 Apr;86(6):509-16.

9 Belarmino G, Gonzalez MC, Torrinhas RS, Sala P, Andraus W, D’Albuquerque LA, et al. Phase angle obtained by bioelectrical impedance analysis independently predicts mortality in patients with cirrhosis. World J Hepatol. 2017 Mar;9(7):401-8.

10 Italian Multicentre Cooperative Project on Nutrition in Liver Cirrhosis. Nutritional status in cirrhosis. J Hepatol. 1994 Sep;21(3): $317-25$.

11 Montano-Loza AJ, Meza-Junco J, Prado CM, Lieffers JR, Baracos VE, Bain VG, et al. Muscle wasting is associated with mortality in patients with cirrhosis. Clin Gastroenterol Hepatol. $2012 \mathrm{Feb} ; 10(2): 166-73$.

12 Lai JC, Dodge JL, Sen S, Covinsky K, Feng S. Functional decline in patients with cirrhosis awaiting liver transplantation: results from the functional assessment in liver transplantation (FrAILT) study. Hepatology. 2016 Feb; 63(2):574-80.

13 Dharancy S, Lemyze M, Boleslawski E, Neviere R, Declerck N, Canva V, et al. Impact of impaired aerobic capacity on liver transplant candidates. Transplantation. 2008 Oct;86(8): 1077-83.

14 Painter PL, Luetkemeier MJ, Moore GE, Dibble SL, Green GA, Myll JO, et al. Health-related fitness and quality of life in organ transplant recipients. Transplantation. 1997 Dec; 64(12):1795-800
15 Allard JP, Chau J, Sandokji K, Blendis LM, Wong F. Effects of ascites resolution after successful TIPS on nutrition in cirrhotic patients with refractory ascites. Am J Gastroenterol. 2001 Aug;96(8):2442-7.

16 Plauth M, Schütz T, Buckendahl DP, Kreymann G, Pirlich M, Grüngreiff S, et al. Weight gain after transjugular intrahepatic portosystemic shunt is associated with improvement in body composition in malnourished patients with cirrhosis and hypermetabolism. J Hepatol. 2004 Feb;40(2):228-33.

17 Levine JA, Harris MM, Morgan MY. Energy expenditure in chronic alcohol abuse. Eur J Clin Invest. 2000 Sep;30(9):779-86.

18 Dunn MA, Josbeno DA, Schmotzer AR, Tevar $\mathrm{AD}$, DiMartini $\mathrm{AF}$, Landsittel DP, et al. The gap between clinically assessed physical performance and objective physical activity in liver transplant candidates. Liver Transpl. 2016 Oct;22(10):1324-32.

19 Swart GR, Zillikens MC, van Vuure JK, van den Berg JW. Effect of a late evening meal on nitrogen balance in patients with cirrhosis of the liver. BMJ. 1989 Nov;299(6709):1202-3.

20 Olde Damink SW, Jalan R, Deutz NE, Dejong $\mathrm{CH}$, Redhead DN, Hynd P, et al. Isoleucine infusion during "simulated" upper gastrointestinal bleeding improves liver and muscle protein synthesis in cirrhotic patients. Hepatology. 2007 Mar;45(3):560-8.

21 Mehanna HM, Moledina J, Travis J. Refeeding syndrome: what it is, and how to prevent and treat it. BMJ. 2008 Jun;336(7659):1495-8.

22 Cabré E, González-Huix F, Abad-Lacruz A, Esteve M, Acero D, Fernandez-Bañares F, et al. Effect of total enteral nutrition on the short-term outcome of severely malnourished cirrhotics. A randomized controlled trial. Gastroenterology. 1990 Mar;98(3):715-20.

23 Kearns PJ, Young H, Garcia G, Blaschke T, O'Hanlon G, Rinki M, et al. Accelerated improvement of alcoholic liver disease with enteral nutrition. Gastroenterology. 1992 Jan; 102(1):200-5.

24 Córdoba J, López-Hellín J, Planas M, Sabín P, Sanpedro F, Castro F, et al. Normal protein diet for episodic hepatic encephalopathy: results of a randomized study. J Hepatol. 2004 Jul;41(1):38-43.

25 Plank LD, Gane EJ, Peng S, Muthu C, Mathur S, Gillanders L, et al. Nocturnal nutritional supplementation improves total body protein status of patients with liver cirrhosis: a randomized 12-month trial. Hepatology. 2008 Aug;48(2):557-66

26 Horst D, Grace ND, Conn HO, Schiff E, Schenker S, Viteri A, et al. Comparison of dietary protein with an oral, branched chainenriched amino acid supplement in chronic portal-systemic encephalopathy: a randomized controlled trial. Hepatology. 1984 MarApr;4(2):279-87.

27 Marchesini G, Bianchi G, Merli M, Amodio P, Panella C, Loguercio C, et al.; Italian BCAA Study Group. Nutritional supplementation with branched-chain amino acids in advanced cirrhosis: a double-blind, randomized trial. Gastroenterology. 2003 Jun; 124(7): 1792-801.
28 Muto Y, Sato S, Watanabe A, Moriwaki H, Suzuki K, Kato A, et al.; Long-Term Survival Study Group. Effects of oral branched-chain amino acid granules on event-free survival in patients with liver cirrhosis. Clin Gastroenterol Hepatol. 2005 Jul;3(7):705-13.

29 Naylor CD, O’Rourke K, Detsky AS, Baker JP. Parenteral nutrition with branched-chain amino acids in hepatic encephalopathy. A meta-analysis. Gastroenterology. 1989 Oct; 97(4):1033-42.

30 Merli M, Nicolini G, Angeloni S, Riggio O. Malnutrition is a risk factor in cirrhotic patients undergoing surgery. Nutrition. 2002 Nov-Dec;18(11-12):978-86.

31 Weimann A, Braga M, Carli F, Higashiguchi T, Hübner M, Klek S, et al. ESPEN guideline: clinical nutrition in surgery. Clin Nutr. 2017 Jun;36(3):623-50.

32 Voron T, Tselikas L, Pietrasz D, Pigneur F, Laurent A, Compagnon P, et al. Sarcopenia Impacts on Short- and Long-term Results of Hepatectomy for Hepatocellular Carcinoma. Ann Surg. 2015 Jun;261(6):1173-83.

33 Selberg O, Böttcher J, Tusch G, Pichlmayr R, Henkel E, Müller MJ. Identification of highand low-risk patients before liver transplantation: a prospective cohort study of nutritional and metabolic parameters in 150 patients. Hepatology. 1997 Mar;25(3):652-7.

34 Merli M, Giusto M, Gentili F, Novelli G, Ferretti G, Riggio O, et al. Nutritional status: its influence on the outcome of patients undergoing liver transplantation. Liver Int. 2010 Feb;30(2):208-14.

35 Kalafateli M, Mantzoukis K, Choi Yau Y, Mohammad AO, Arora S, Rodrigues S, et al. Malnutrition and sarcopenia predict post-liver transplantation outcomes independently of the Model for End-stage Liver Disease score. J Cachexia Sarcopenia Muscle. 2017 Feb;8(1):113-21.

36 Hanai T, Shiraki M, Nishimura K, Ohnishi S, Imai K, Suetsugu A, et al. Sarcopenia impairs prognosis of patients with liver cirrhosis. Nutrition. 2015 Jan;31(1):193-9.

37 Englesbe MJ, Patel SP, He K, Lynch RJ, Schaubel DE, Harbaugh C, et al. Sarcopenia and mortality after liver transplantation. J Am Coll Surg. 2010 Aug;211(2):271-8.

38 Tsien C, Garber A, Narayanan A, Shah SN, Barnes D, Eghtesad B, et al. Post-liver transplantation sarcopenia in cirrhosis: a prospective evaluation. J Gastroenterol Hepatol. 2014 Jun;29(6):1250-7.

39 Plank LD, McCall JL, Gane EJ, Rafique M, Gillanders LK, McIlroy K, et al. Pre- and postoperative immunonutrition in patients undergoing liver transplantation: a pilot study of safety and efficacy. Clin Nutr. 2005 Apr;24(2):288-96.

40 Le Cornu KA, McKiernan FJ, Kapadia SA, Neuberger JM. A prospective randomized study of preoperative nutritional supplementation in patients awaiting elective orthotopic liver transplantation. Transplantation. 2000 Apr;69(7):1364-9.

41 Plank LD, Mathur S, Gane EJ, Peng SL, Gillanders LK, McIlroy K, et al. Perioperative immunonutrition in patients undergoing liver transplantation: a randomized double-blind trial. Hepatology. 2015 Feb;61(2):639-47.
Nutritional Intervention in Chronic Liver Failure
Visc Med 2019;35:292-298

DOI: $10.1159 / 000502125$ 
42 Kaido T, Mori A, Oike F, Mizumoto M, Ogura $\mathrm{Y}$, Hata $\mathrm{K}$, et al. Impact of pretransplant nutritional status in patients undergoing liver transplantation. Hepatogastroenterology. 2010 Nov-Dec;57(104):1489-92.

43 Chin SE, Shepherd RW, Thomas BJ, Cleghorn GJ, Patrick MK, Wilcox JA, et al. Nutritional support in children with end-stage liver disease: a randomized crossover trial of a branched-chain amino acid supplement. Am J Clin Nutr. 1992 Jul;56(1):158-63.

44 Rayes N, Seehofer D, Hansen S, Boucsein K, Müller AR, Serke S, et al. Early enteral supply of lactobacillus and fiber versus selective bow- el decontamination: a controlled trial in liver transplant recipients. Transplantation. 2002 Jul;74(1):123-7.

45 Laryea M, Watt KD, Molinari M, Walsh MJ, McAlister VC, Marotta PJ, et al. Metabolic syndrome in liver transplant recipients: prevalence and association with major vascular events. Liver Transpl. 2007 Aug;13(8):110914.

46 Schütz T, Hudjetz H, Roske AE, Katzorke C, Kreymann G, Budde K, et al. Weight gain in long-term survivors of kidney or liver transplantation-another paradigm of sarcopenic obesity? Nutrition. 2012 Apr;28(4):378-83.
47 Berzigotti A, Garcia-Tsao G, Bosch J, Grace ND, Burroughs AK, Morillas R, et al.; Portal Hypertension Collaborative Group. Obesity is an independent risk factor for clinical decompensation in patients with cirrhosis. Hepatology. 2011 Aug;54(2):555-61.

48 Berzigotti A, Albillos A, Villanueva C, Genescá J, Ardevol A, Augustín S, et al.; Ciberehd SportDiet Collaborative Group. Effects of an intensive lifestyle intervention program on portal hypertension in patients with cirrhosis and obesity: the SportDiet study. Hepatology. 2017 Apr;65(4):1293305 . 